UDC 519.6

$10.23947 / 2587-8999-2019-1-1-35-49$

\title{
Mathematical modeling of the delay process in regulation of population dynamics based on the theory of cellular automation *
}

\author{
A.V. Nikitina, V.M. Kozlov**, A.A. Filina***
}

Southern Federal University, Taganrog, Russia

Supercomputers and Neurocomputers Research Center, Co. Ltd., Taganrog, Russia

The paper covers the research and parameterization of the delay effect in regulation of biological kinetics processes for interacting populations, including the modification of the mathematical model to describe the development of population fluctuations. Numerical implementation of the modified Conway algorithm for a cellular automaton with a ternary state of cells was developed for analysis the model scenarios of dynamics of nonlinear interacting biological populations, taking into account factors that have a significant influence on the nature of researched processes. The transformation conditions of the cells' state show that the formalized delay can refer to the dynamics of interaction of species and supporting the living conditions of the environment. A numerical implementation of a fundamentally different version of the cellular automaton was proposed. The cellular automaton allow modeling the processes of population dynamics regulation taking into account the delay effect on the basis of three dynamically interacting factors: ontogenetic delay, the necessary to restore resources, and diffusion component depending on the development rate of individuals in the population.

Keywords: cellular automaton, population dynamics, delay effect, mathematical model, algorithm, program.

Introduction. In the 70-s of XX century Kolmogorov A.N. assumed that with «the development of modern computing in many cases the examination of actual phenomena is reasonable conduct, avoiding the intermediate stage of it stylization in the spirit of the mathematics of the infinite and continuous, and passing directly to discrete models». Indeed, there is a large variety of mathematical systems based on the principle of fine-grained parallelism, and, most importantly, there were software and hardware systems that can simulate the operation of such systems today [1].

The main distinctive feature of systems with fine-grained parallelism is the possibility of simultaneous (parallel) changes in conditions of the entire system, while each section of it interacts only with its immediate neighbors. Due to this property, the events occurring at the micro level can associate with changes in the macro-level of the simulated object.

The classical system with fine-grained parallelism is a cellular automaton - a discrete model, which is a grid of arbitrary dimension. Each cell of grid at any given time can take one of a finite set of conditions with a given rule of cell transition from one condition to another.

\footnotetext{
* The paper was supported with the financial support by the grant № 17-11-01286 of the Russian Science Foundation.

** E-mail: nikitina.vm@gmail.com.

*** E-mail: j.a.s.s.y@mail.ru.
} 
The idea of cellular automation was appeared in the late 40-s of XX century. It was conceived and formulated by John von Neumann and Conrad Zuse independently as a universal computing environment for constructing, analyzing and comparing the characteristics of different algorithms.

The definition of cellular automata is given in the paper of Toffoli T., Margolus N. [2]: «Cellular automata are discrete dynamical systems whose behavior is fully defined in terms of local dependencies. To a large extent, this is also the case for a large class of continuous dynamical systems defined by partial differential equations. In this sense, cellular automata in computer science are analogous to the physical concept of «field», and cellular automata can be thought of as a stylized world. The space is represented by a uniform grid, each cell of which contains several bits of data; time goes forward in discrete steps, and the laws of the world are expressed by a single set of rules or a small reference table, by which any cell at each step calculates its new condition by the states of its close neighbors. Thus, the laws of the system are local and the same everywhere. «Local» means that in order to find out what will happen here a moment later, it is enough to look at the condition of immediate environment: no long-range action is allowed. «Sameness» means that the laws are the same everywhere: I can distinguish one place from another only by the shape of the landscape, not by any difference in the laws». Note that cellular automata are not just machines performing with a field divided into cells. The field of application of cellular automata is almost limitless: from the simplest «cross-zero» to artificial intelligence. The theme of cellular automata is very relevant, as it can lead to the solution of many issues in the world.

A two-dimensional cellular automation can be defined as a set of finite automata on a surface indicated with integer coordinates $(i, j)$, each of which can be in one of conditions $\sigma_{i, j}$ :

$$
\sigma_{i, j} \in \sum \equiv\{0,1,2 \ldots k-1, k\} \text {. }
$$

The change of automation conditions occurs according to the rule of transition

$$
\sigma_{i, j}(t+1)=\phi\left(\sigma_{k, l}(t) \mid(k, l) \in N(i, j)\right),
$$

where $N(i, j)$ is some neighborhood of a point $(i, j)$.

For example, the von Neumann neighborhood:

$$
N_{N}^{1}(i, j)=\{(k, l)|| i-k|+| j-l \mid \leq 1\},
$$

and the Moore neighborhood:

$$
N_{M}^{1}(i, j)=\{(k, l)|| i-k|\leq 1,| j-l \mid \leq 1\} .
$$

Four types of cellular automation were proposed by Stephen Wolfram in the book «A New Kind of Science». According to it, all cellular automation can be separate depending on the type of their evolution [3]. The Wolfram classification was the first attempt to classify the rules themselves rather than the types of behavior of the rules separately.

The cellular automaton, known as «Conway's Game of Life» [4], was popularized by John Conway to explain the processes of self-organization in various natural sciences and simply as a visual model in teaching programming. Popularity is explained by only two calculation rules of the next generation of group of cells which can be alive or dead: if there's a dead cell with three living, the dead becomes alive; a living cell remains in its state if there're two or three living cells nearby. 
The playing field may be limited, withdrawn - in the form of a computer simulation of the torus surface. Such technique in the simulation is called the setting of boundary conditions of cyclic type or periodic boundary conditions (the most common option) or infinite, as originally believed Conway. At the same time, the simplicity of the rules with binary cell division provides a huge variety of forms and interesting variants of the arrangement of living cells in the first generation, which lead to stable or periodic variants of the final arrangement, called figures. There is a game modification with the continuous space without cells with a very impressive visual implementation. The situations that arise in the course of the game invented by him are very similar to the real processes that occur at the birth, development and death of a colony of living organisms. They are born with a favorable combination of relevant factors and die if the conditions of their existence become unbearable. The conditions of birth and death are determined exclusively by the mutual arrangement of participants.

Although the game consists of simple rules, nevertheless, it attracts the attention of scientists for more than forty years. The game «Life» and its modifications influenced (in some cases mutually) many sections of such exact Sciences as mathematics, computer science, physics. In addition, many of the patterns found in the game have their analogies in other, sometimes completely «nonmathematical» disciplines. Perhaps, this game is connected with other scientific phenomena, including those about which modern science is still unknown. It is also possible that the laws of «Nature and Society» that are not open today will become more understandable thanks to «Life» and its modifications.

Thus, cellular automata have found and are widely used in many spheres of human activity, many of problems which became possible to solve only with the help of a computer.

The use of cellular automata to research the processes of biological kinetics is reflected in the historically first model of exponential population growth $N(t)=N(0) e^{r t}$. To describe changes in the state of small populations, no separate formalization of the existing mechanisms of regulation in the functional form was assumed, only at the level of correction of the basic value of the reproductive parameter $r$ [5].

The parameter $r$ is a - reproductive potential (also known as «malthusian parameter») and defined as the difference between instant birth and death $r=\alpha-\beta$. It was supposed a priori $r>0$ irrespective from $t$. The exponential growth equation $N=r N_{t}$ has long been unused, referred to as an anomaly in the history of mathematical biology, although it is obvious from many examples of alien species infestations that the properties of reproductive activity simply cannot be preserved $\forall t$.

For example, a system of deterministic equations describing the petroleum hydrocarbons biodegradation processes by introducing the Chlorella vulgaris Beijer green algae into the water on the basis of combined methods of mathematical modeling using the stochastic approach, with its probabilistic submodels, takes into account the simultaneous influence of external factors, including the spatial distribution of salinity, temperature and illumination, on the rate of mass transfer:

$$
\left(P_{i}\right)_{t}^{\prime}+\operatorname{div}\left(\mathbf{u} P_{i}\right)=\mu_{i} \Delta P_{i}+\varphi_{i}, i \in \overline{1,4}
$$

where $P_{i}$ is a concentration of $i$-th component: 1 is the petroleum, 2 is the biogenic matter, 3, 4 are the Chlorella vulgaris Beijer green algae and its metabolite; $\mathbf{u}$ is the velocity vector of water flow; $\mu_{i}$ are diffusion coefficients; $\varphi_{i}$ is a chemical-biological source. 
If the second equation of the considered system taking into account the fluctuations of the environment has the form:

$$
\dot{P}_{2}=(\alpha-\beta+y(t)) P_{2}, \quad m(t)=P_{2}^{0} e^{(\alpha-\beta) t}, \sigma^{2}(t)=P_{2}^{0} e^{2(\alpha-\beta) t}\left(e^{\sigma^{2} t}-1\right),
$$

where $\alpha, \beta$ are growth rate and mortality of phytoplankton; $r=\alpha-\beta \quad P_{2}^{0}$ is a concentration of $P_{2}$ at the initial time; $m(t), \sigma^{2}(t)$ are the mathematical expectation and variance of fluctuations $y(t)$, that at $r<\sigma^{2}$ the probability of degeneration of the Chlorella vulgaris Beijer population over time increases, in an effort to limit the unit - the population is probability unstable, i.e. long enough effects of disturbances are most likely to lead to her death. At $r>\sigma^{2}$ the probability of degeneration decreases, and at $t \rightarrow \infty$ the population tends to zero - the population in this sense is stable.

The adequacy of probabilistic observational models can be checked using the randomness criterion, which takes into account the variance values of a number of actual parameters and its random component caused by the influence of randomness elements [6].

In the future, Multispecies interaction models were developed. One of the problems was the confirmation of the existence of closed cyclic trajectories for the number of opposing populations in practice of observations or in experiments, which predicts the well-known «predator-prey» model by Lotka-Volterra.

The oscillations of two species were obtained in experiments of Utid S. for another type of biological interaction «parasite-host». To explain the contradictions, the hypothesis arose that the effect of self-regulation does not act from the current state, but from the one, existed in the past and manifests itself after a while. This hypothesis was suitable for the existing mathematical means of modeling of elastic deformations - differential equations with a deviating argument.

As a result of the observations and laboratory experiments it was found that population fluctuations may also occur in isolated populations in the absence of interspecific trophic interactions [7]. The logistic equation with delay was proposed by Hutchinson G. for formation the appearance of population oscillations of a single-species self-regulating system [8]:

$$
N_{t}^{\prime}=r N(t)(1-N(t-\tau) / K)
$$

where $t$ is the time; $N$ is the number of individuals in the population; $r$ is a reproductive characteristic; $K$ is a supporting habitat capacity; $\tau$ is the delay parameter.

The delay parameter $\tau$ in this equation is a characteristic of regulation, i.e. the regulating parameter of use and restoration of resources or accumulation/disintegration of toxic products of metabolism, not connected with the age of puberty. The Andronov-Hopf bifurcation is performed at increasing the value of delay $\tau$ (or the reproductive characteristic $r$ ) [9].

It is known that in most cases, the effect of delay was associated with the duration and stages of the formation of adult mature organisms. If the delay is some much then the critical value, the resulting cycle quickly acquires a relaxation form with very low and long minimums. A large number of equation modification (1) was proposed for improving the characteristics of the oscillation model cycle. The «food-limited equation» including periodically dynamic coefficients was the most famous among them [10]. This suggests that the method of harmonization of models and observational data has reached an impasse. 


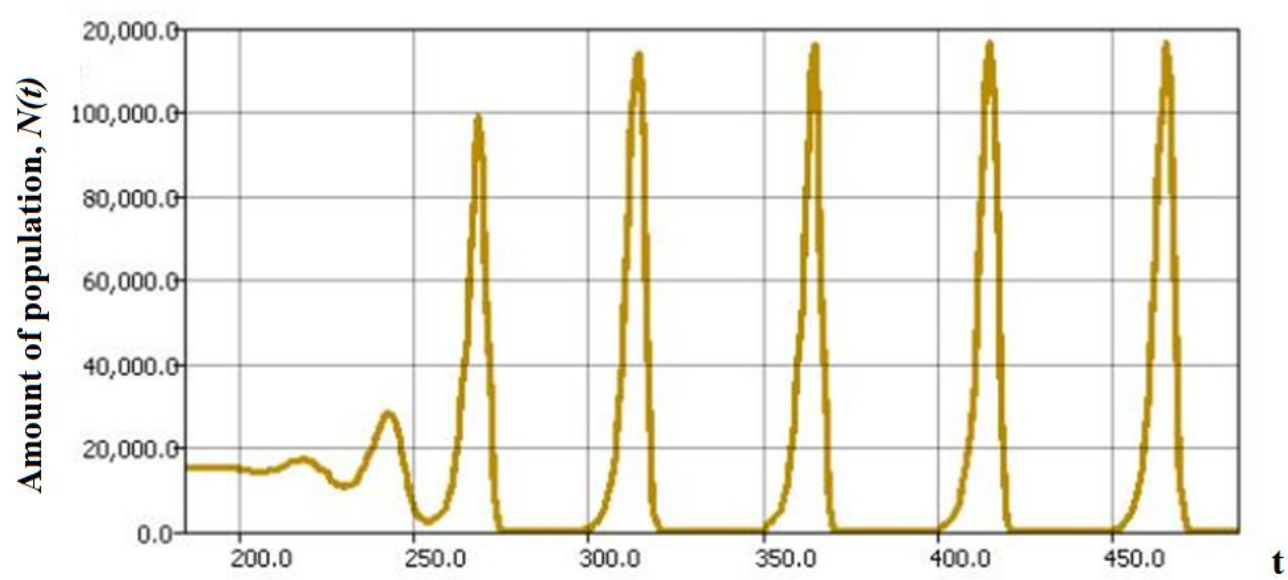

Fig. 1. Relaxation cycle in the Hutchinson equation, $K=15000$.

According to experiments, conducted by the australian entomologist Nicholson with the laboratory population of flies, complex fluctuations of generational and regime change in behavior were occurred if the quantity and the regularity of receipt feed were changed; according to the modern analysis two frequency components were assigned in the oscillations [11].

However, in this case, the amount of feed is not a bifurcation parameter for the equation (1) considered above. A value $K$ scales the amplitude of oscillations and represents the limit of the «ecological level». It's corresponded to the indicator of nutrient availability in (1). The fecundity and the time of passage of the stages of individual ontogenesis can be constant for the period of observation on average. It is obvious that in the experiment it was possible to simulate the change in the recovery rate of biological resources. According to the fact that the lack of food directly affects the mortality of larvae, it value is not isolated in the Hutchinson equation modifications. Therefore, it's necessary to take into account the instantaneous loss from the current population $\beta$ (additional bifurcation parameter) was required for better agreement of experimental data simultaneously with the suppression of competition reproductive potential.

It was proposed a fundamentally different equation with delay, known as «Nicholson's blowflies equation» with the exponential nonlinearity, responsible for the self-regulation of reproduction efficiency [12]:

$$
N_{t}^{\prime}=\Upsilon N(t-\tau) e^{-\gamma N(t-\tau)}-\beta N(t),(\Upsilon, \gamma, \beta=\text { const }>0),
$$

where $\gamma$ is a characteristics of the population with the maximum effective reproduction.

The complex oscillations were occurred at the large values $\tau$ ( $\tau=15 ; \beta=0.3$ ); the damped oscillations were occurred with a smaller delay and smaller values $\beta \square 1(\tau=8, \beta=0,015)$ - it's the scenario of soft completion of alien species invasive process with a single peak

The invasion of Mnemiopsis leidyi in the Black Sea refers to such scenario; but the dynamics of its number after entering the Caspian Sea does not fit into the known models. Mnemiopsis is a «short circuit breakers» in marine ecosystems, intercepting and mineralize flows of zooplankton organic matter, regenerate nutrients and thus stimulate the development of phytoplankton. 
After the introduction of ctenophore in the Azov Sea the primary production was doubled with a concomitant increasing the organic matter in water and sediments and its turnover. One of the consequences of changes in the trophic chains in the Azov Sea ecosystem as a result of ctenophore introduction is an increase of detritus proportion [13]. M. leidyi can indirectly regulate the dynamics and distribution of summer phytoplankton through the consumption mechanism of zooplanktersphytophages, producing the «cascade» effect on the lowest trophic levels, through the zooplankton on phytoplankton and the chlorella «a». Eating of meroplankton by Mnemiopsis (larvae of benthic animals) and demersal plankton leads to decreasing of benthic biomass.

At modeling of hydrological processes (the interaction of plankton and ctenophores) in a shallow water - the Azov Sea - we take into account spatial distribution of salinity and temperature. The amount of Mnemiopsis depends on the range of its penetration and determined by the direction and velocity of wind currents that contribute to the drift of waters with high salinity. Mnemiopsis can live and reproduce only at salinity above 4.3\%o (for the Caspian Sea) [14]. The distribution of Mnemiopsis in the Azov Sea is limited by isogaline 3\%, due to its penetration from the Black Sea, where it's re-populated every year in spring or early summer, and lives until October, then dying out when temperature drops below $4^{\circ} \mathrm{C}$.

Full-scale measurements obtained during the expedition in the Azov-Black Sea basin, and data of the «Analytical GIS» portal, developed by the Institute for information transmission problems of RAS (IITP RAS, Moscow) were used at modeling [15].

The model for describing the ecological and biological process of interaction between ctenophores and plankton has the form [16, 17]:

$$
\begin{aligned}
& \left(P_{i}\right)_{t}{ }^{\prime}+\frac{1}{2} \sum_{\alpha=1}^{3}\left\{U_{\alpha}\left(P_{i}\right)_{x_{\alpha}}{ }^{\prime}+\left(U_{\alpha} P_{i}\right)_{x_{\alpha}}{ }^{\prime}\right\}=\mu_{i} \Delta P_{i}+\frac{\partial}{\partial x_{3}}\left(v_{i} \frac{\partial P_{i}}{\partial z}\right)+\psi_{i}, i \in \overline{1,9} . \\
& \psi_{1}\left(P_{1}, P_{2}, P_{3}\right)=\left\{\alpha_{1} P_{3}-\delta_{1} P_{2}-\varepsilon_{1}\right\} P_{1}, \psi_{2}\left(P_{1}, P_{2}\right)=\left\{\alpha_{2} P_{1}-\varepsilon_{2}\right\} P_{2}, \\
& \psi_{3}\left(P_{1}, P_{3}, P_{4}\right)=\left\{\alpha_{3} P_{4}-\delta_{3} P_{1}-\varepsilon_{3}\right\} P_{3}, \psi_{4}\left(P_{3}, P_{4}, P_{5}\right)=\left\{\alpha_{4} P_{5}-\delta_{4} P_{3}-\varepsilon_{4}\right\} P_{4}, \alpha_{4}=\left(\alpha_{04}+\gamma_{4} P_{6}\right) \\
& \psi_{5}\left(P_{1}, P_{2}, \ldots, P_{9}\right)=\sum_{i=1, i \neq 5}^{9} \varepsilon_{i} P_{i}-\delta_{5} P_{4} P_{5}+B\left(\bar{P}_{5}-P_{5}\right)+f, \\
& \psi_{m}\left(P_{1}, P_{2}, P_{3}, P_{4}, P_{6}, \ldots, P_{9}\right)=\sum_{l=1}^{4} k_{l} P_{l}-\varepsilon_{m} P_{m} ; m \in \overline{6,9},
\end{aligned}
$$

where $P_{i}$ are concentrations, $i \in \overline{1,9}: 1,2$ are Mnemiopsis leidyi and Beroe ovata ctenophores; 3 is the zooplankton; 4 is the phytoplankton; 5 is the biogenic matter; $6,7,8,9$ are metabolites of ctenophores $(6,7)$ and plankton (zoo- $(8)$ and phyto- $(9)) ; \psi_{i}$ are functions of trophic interactions; $\alpha_{l}$ is the growth function of ctenophores and plankton, $l=\overline{1,4} ; \alpha_{04}, \gamma_{4}$ are the phytoplankton growth rate in the absence of metabolite and the impact parameter; $B$ is the entering velocity of nutrients $P_{5} ; \bar{P}_{5}$ is the maximum possible concentration of nutrients; $\varepsilon_{l}$ is a mortality factor of $l$-th specie; $\varepsilon_{m}$ are coefficients of metabolite decomposition, $m=\overline{6,9} ; k_{l}$ is an excretion rate of $l$-th specie (ctenophores $(l=\overline{1,2})$, zooplankton $(l=3)$, phytoplankton $(l=4)) ; \delta_{1}, \delta_{3}, \delta_{4}$ are coefficients of loss due to eating; 
$f=f\left(x_{1}, x_{2}, x_{3}, t\right)$ is the source function $P_{5}$ (pollution); $\mathbf{u}$ is the velocity field of water flow; $\mathbf{U}=\mathbf{u}+\mathbf{u}_{0 i}, \mathbf{U}=\left(U_{1}, U_{2}, U_{3}\right)$ is the rate of convective transport of matter; $\mathbf{u}_{0 i}$ is the sedimentation rate of $i$-th substance; $\mu_{i} v_{i}$ are diffusion coefficients in horizontal and vertical directions of $i$-th substance.

The computational domain $G$ is a closed basin limited by the undisturbed water surface $\Sigma_{0}$, the bottom $\Sigma_{H}=\Sigma_{H}(x, y)$ and the cylindrical surface $\sigma$ for $0<t \leq T_{0} . \quad \sum=\Sigma_{0} \cup \Sigma_{H} \cup \sigma$ is the piecewise smooth boundary of the domain $G$.

We add boundary conditions to the system (3):

$$
P_{i}=0 н а \sigma, \mathbf{U}_{\mathbf{n}}<0 ;\left(P_{i}\right)_{\mathbf{n}}^{\prime}=\varphi_{i} н а \sigma, \mathbf{U}_{\mathbf{n}} \geq 0 ;\left(P_{i}\right)_{z}^{\prime}=0 н а \Sigma_{0} ;\left(P_{i}\right)_{z}^{\prime}=-\beta_{i} P_{i} \text { на } \Sigma_{H},
$$

where $\beta_{i}$ is an absorption coefficient of $i$-th component by bottom sediments; $\mathbf{n}$ is the vector of the external normal to the surface $\sum$.

Also, we add initial conditions:

$$
\left.P_{i}\right|_{t=0}=P_{i 0}(x, y, z), i=\overline{1,9} \text {. }
$$

Thus, there is a problem of ecological interpretation of delay $\tau$, i.e., the determination of its magnitude with any direct population characteristics or properties of the environment. The analysis showed that taking into account the effect of delay in biological kinetics models can improve the accuracy of predictive modeling of population dynamics.

Continuity of measurement units is not necessary for population dynamics, because there are alternative methods for describing the processes of biological population dynamics, such as the cognitive graphs and cellular automata.

Results of numerical experiments. Rules of operation of new cellular automaton were defined in the paper [18]. Due to it, we can research the influence of the delay effect on the evolution of interacting biological populations. A mathematical game with more complex rules were introduced for illustration the problem of parametric expression of delay action in dynamic models and as a new object for determining the self-organization forms. According to it, the automaton cell has not two, but three acceptable conditions. The cellular automaton in which the parameter, relating to the nature of the occurrence of delayed regulation, will change during the game, simulating the evolutionary adaptation of the community to the emergence of new species, can be designed in the future.

Let's describe the rules of the «oaks-rodents» cellular automaton.

1. A cell field is defined as the same «Life» game (in the closed version). Each cell has 8 adjacent cells. Initially, the oak grows in each cell $\left(N_{1}\right)$. The rodent $\left(N_{2}\right)$ can settle in the cell, containing the oak.

2. Adult rodent can produce $r=2$ offspring every season if also the rodent lives at least one of the adjacent to his cell.

3. If more than 5 cells are occupied around the rodent, the rodent dies from overpopulation, and the oak becomes free.

4. Rodents undermine the roots of the tree. The oak falls, and the rodent dies. Before the fall of the oak, a rodent may breed no more than $k=5$ times. 
5. The offspring of the rodent will become pubescent and will be able to give offspring through the season, if they will take a suitable oak at this moment, otherwise they die. The new rodent occupies the nearest free oak with the least number of occupied adjacent cells, examining the adjacent ones clockwise.

6. The rodent may have migrated for the season to a distance of not more than $l=2$ of the neighboring cells to occupy the oak (similar to the speed of light in the Conway's game).

7. A new oak grows up for $\tau=10$ seasons on place the fallen oak.

Several aspects, related to the phenomenon of delayed regulation, are determined in the transformation rule of cell conditions. Moreover, these factors are warring in the game. We propose to make the parameter $\tau$ as a «manager» to assess the impact in scenarios with slower recovery of resources, which was not in «Life», but is consistent with environmental reality.

The software that implements the operation of the cellular automaton was developed in the C\# object-oriented programming language. Transition rules for cellular automation of the delay regulation are the basis of algorithm of software implementation. For a better research of the model of biological population interacting, all parameters of the cellular automation can dynamically change during the application.

The main window of the developed application with the original interface that allows to dynamically changing the parameters of the cellular automation is given in Fig. 4.

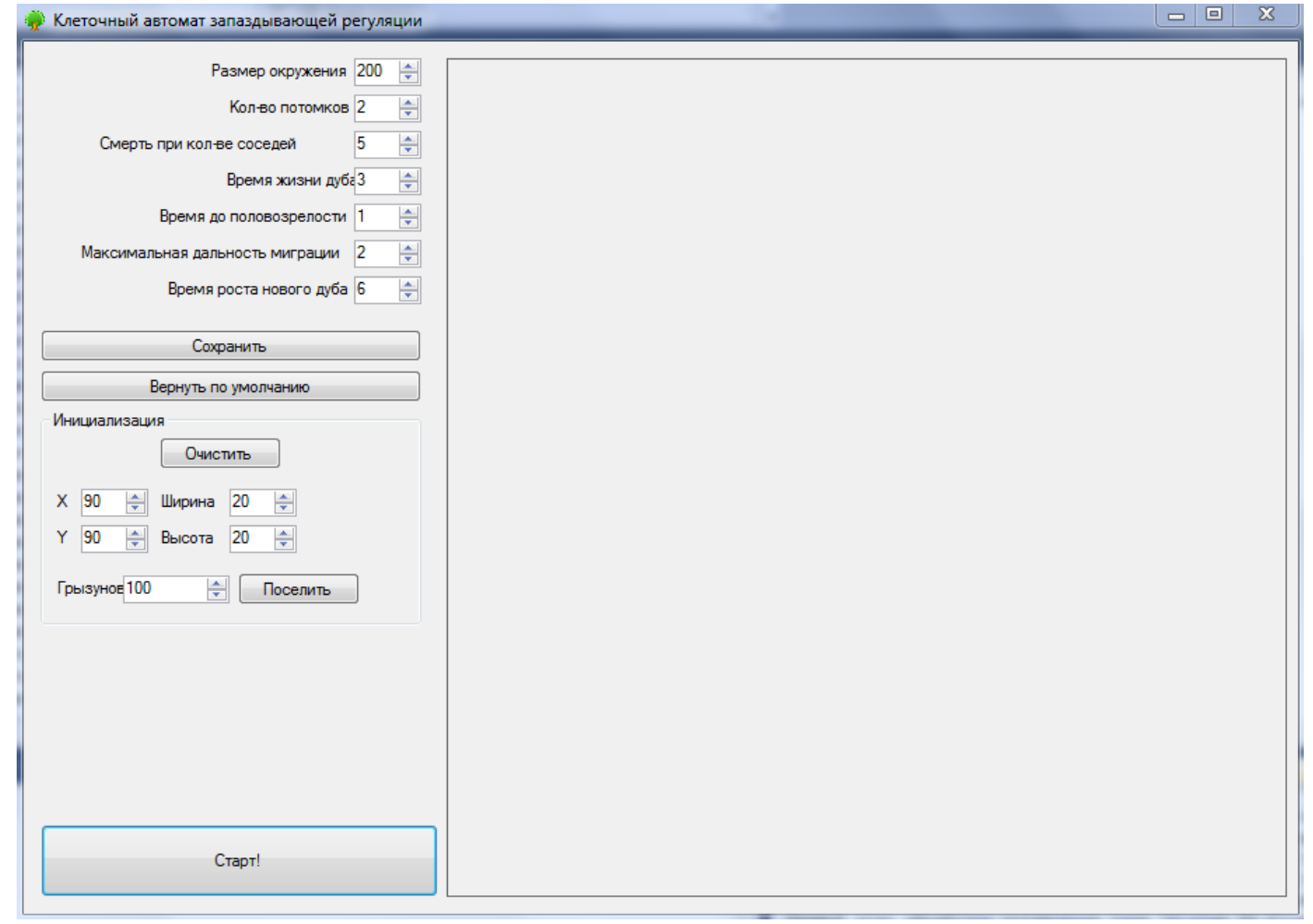

Fig.4. The interface of application.

We conducted a number of experiments with the developed application. Figures 5-8 shows the results of mathematical modeling the evolution process of two interacting species of biological 
populations (the concentration $N_{1}$ denotes by the green color, $N_{2}-$ by the red color) taking into account the delay effect based on the previously introduced transition rules (algorithm) of the cellular automation.

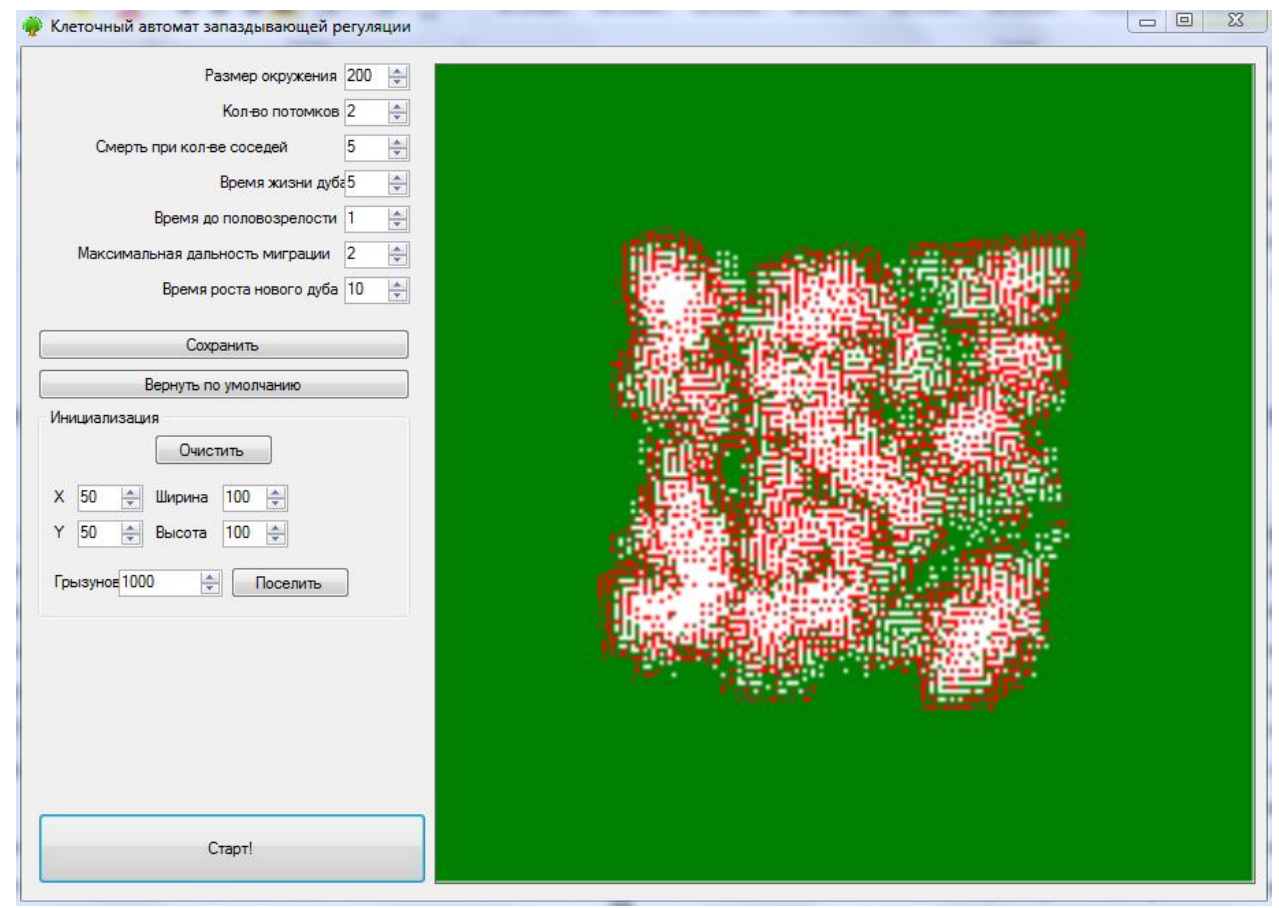

Fig. 5. The process of modeling the interaction of biological populations.

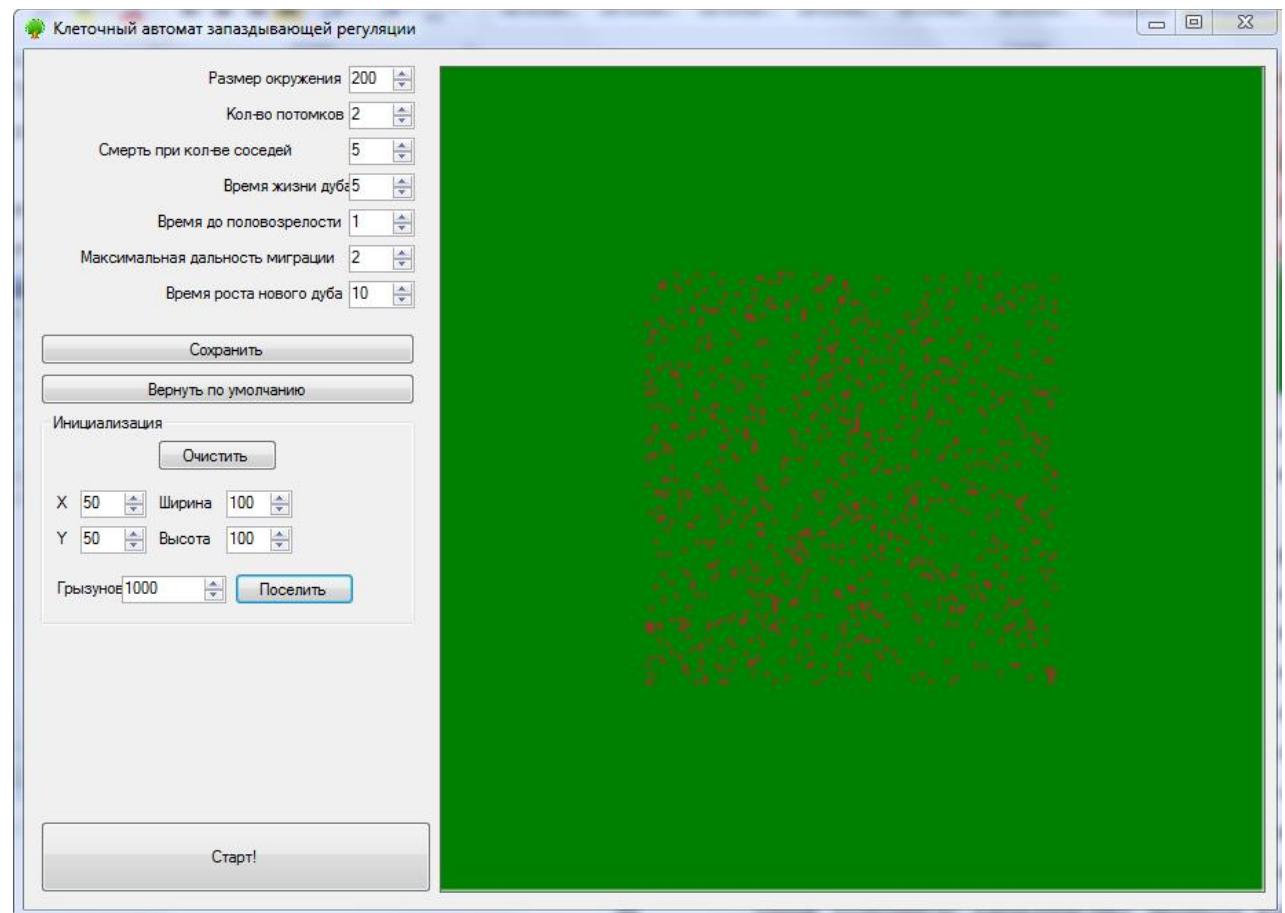

Fig. 6. Changes in the number of interacting populations at the initial time $(t=0)$. 


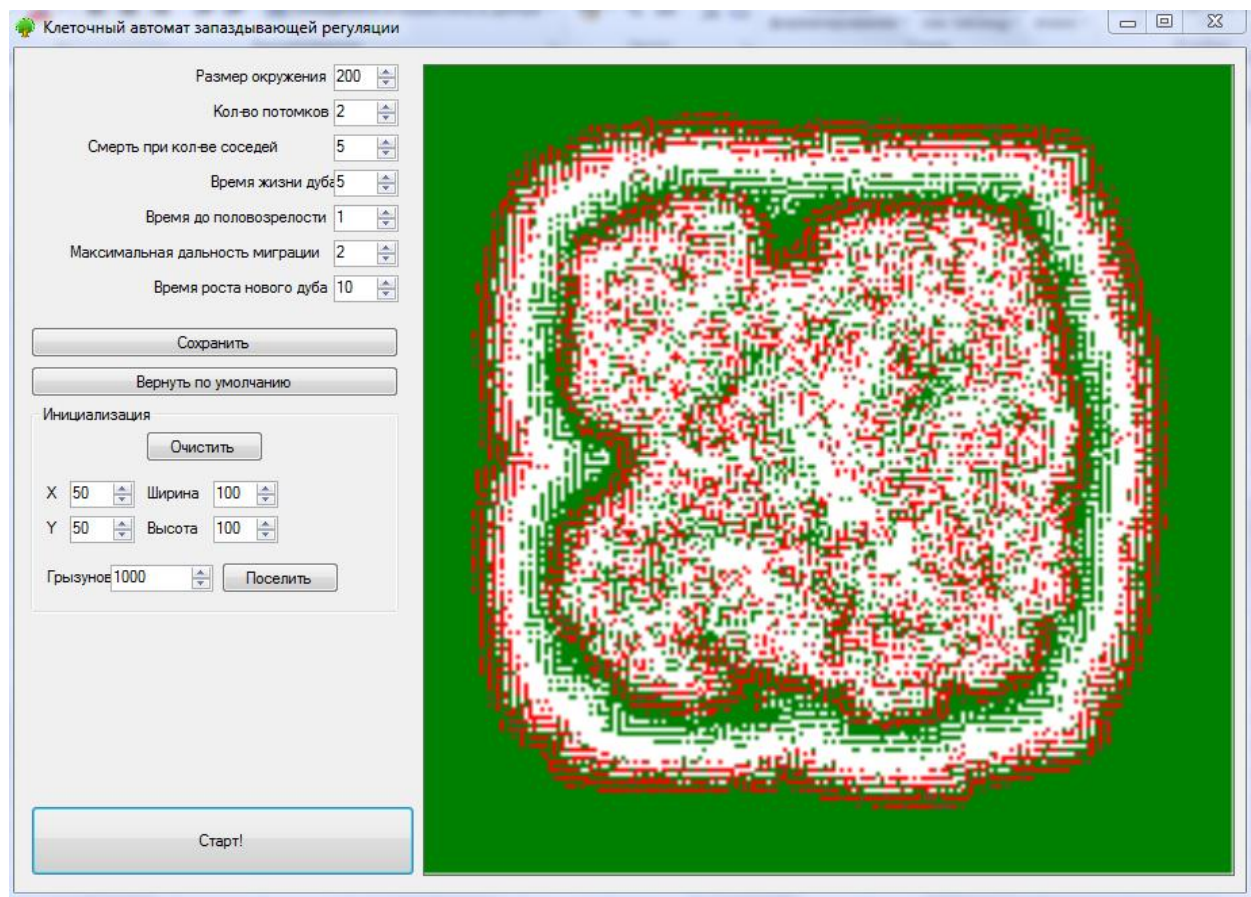

Fig. 7. The intermediate stage of the simulation $(t=50)$.

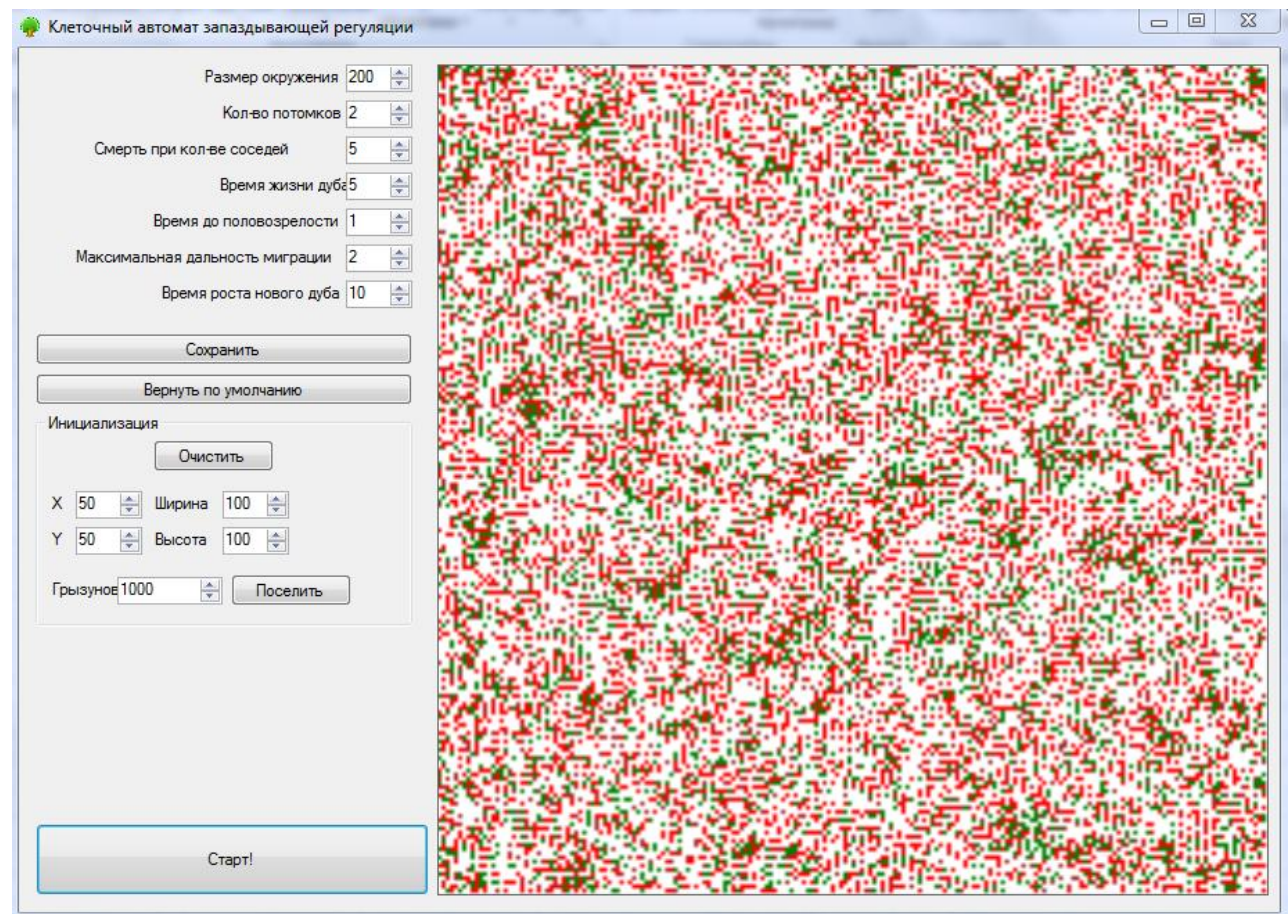

Fig. 8. Changes of the amount of interacting populations $(t=500)$.

Graphs of population amount changes for different values (the time delay parameter) are given in Fig. 9-12. 


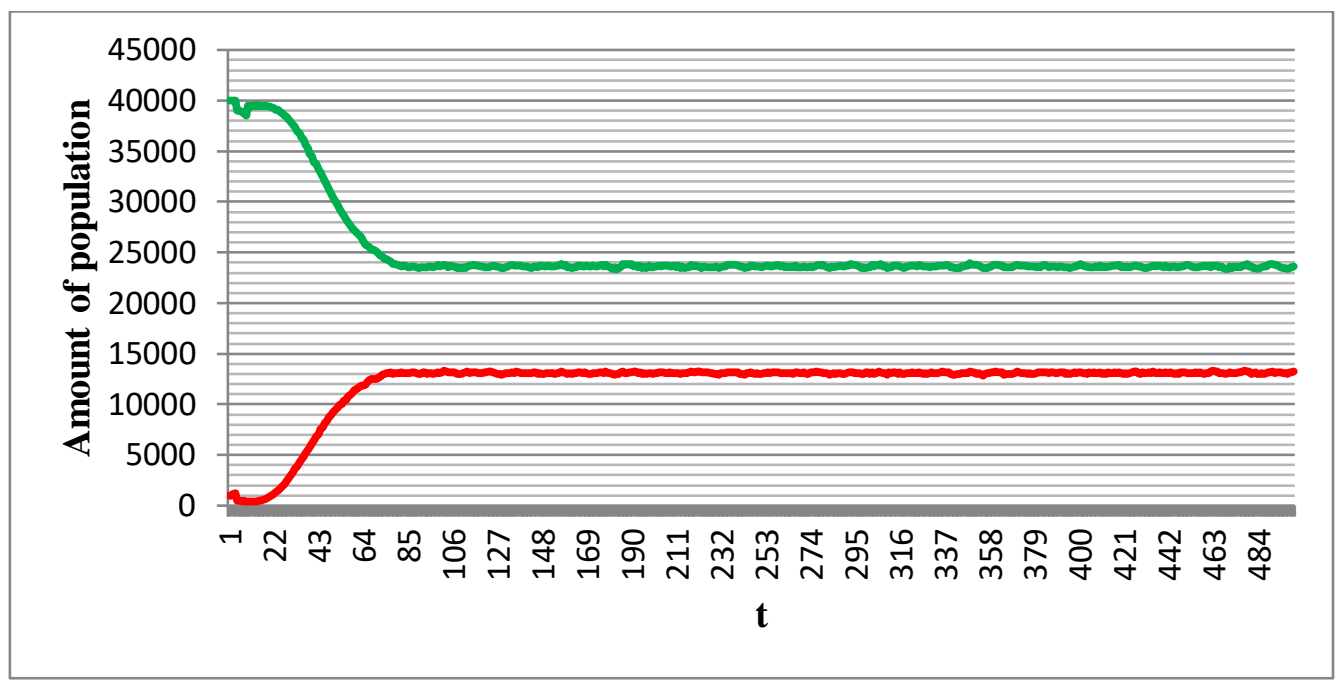

Fig. 9. Changes of population at $\tau=5$.

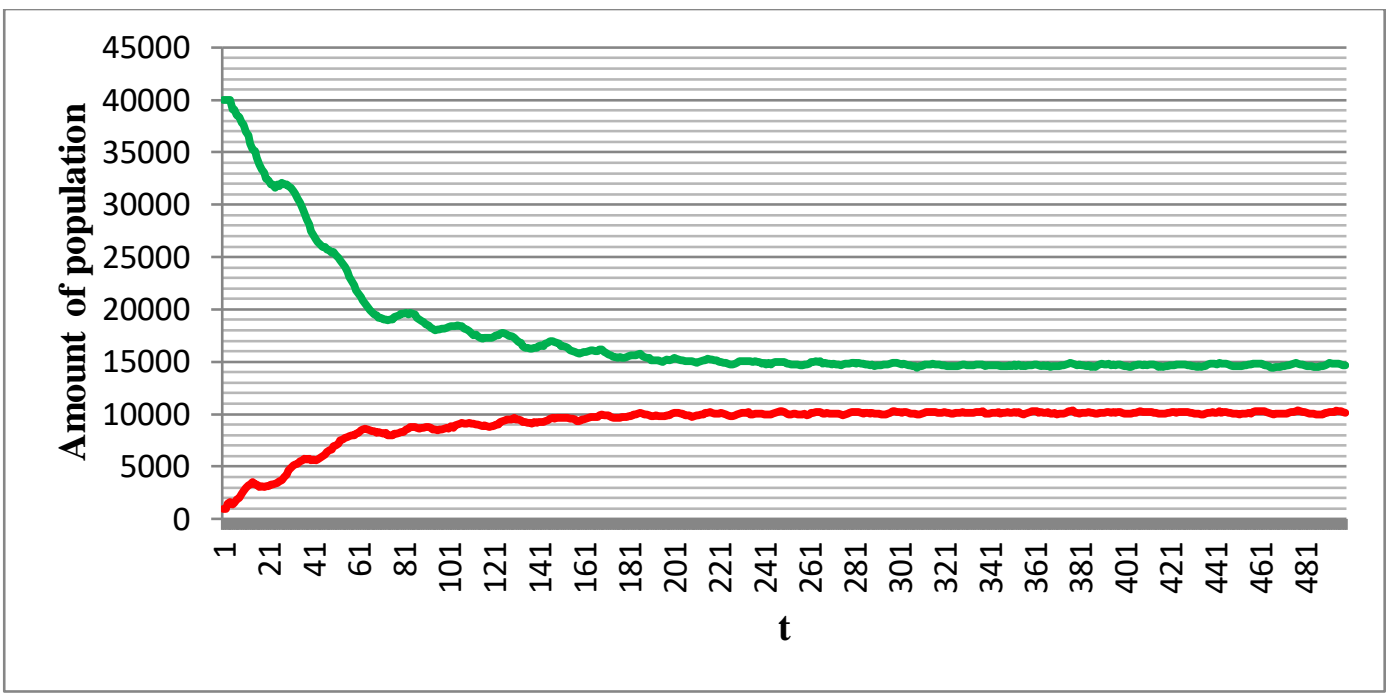

Fig. 10. Changes of population at $\tau=10$.

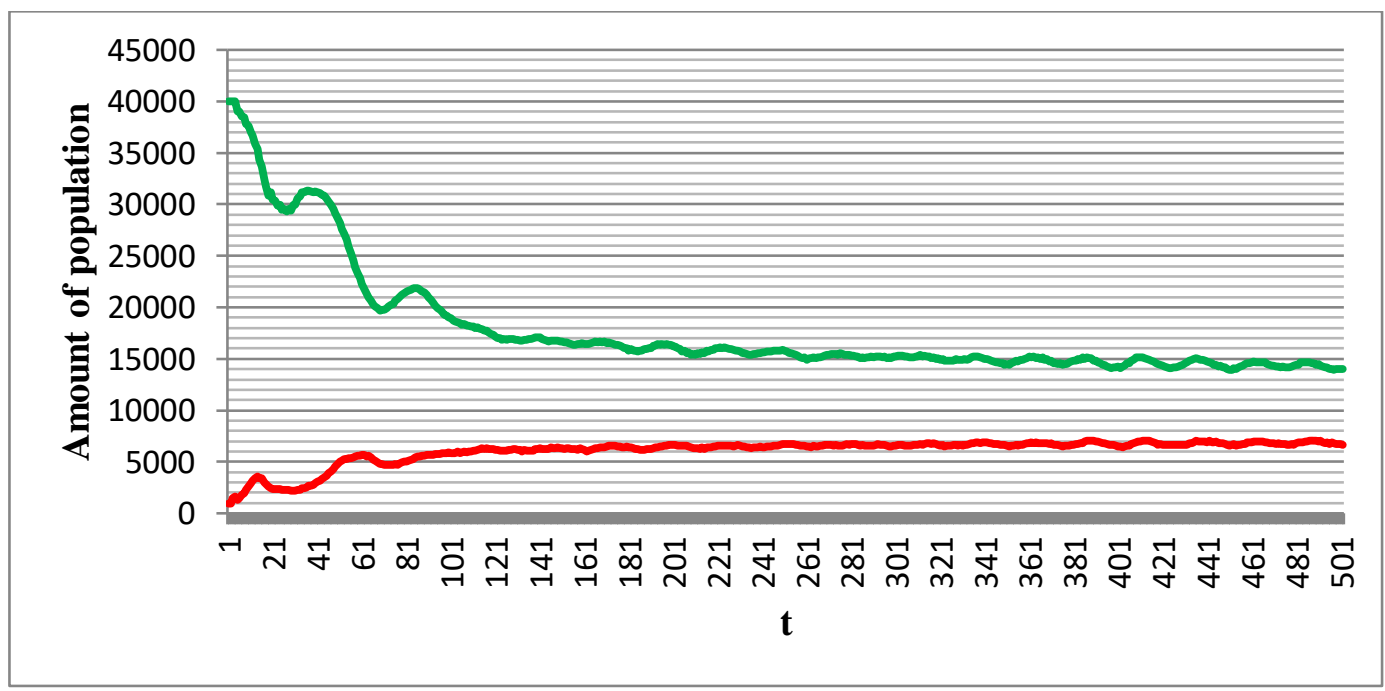

Fig. 11. Changes of population at $\tau=15$. 


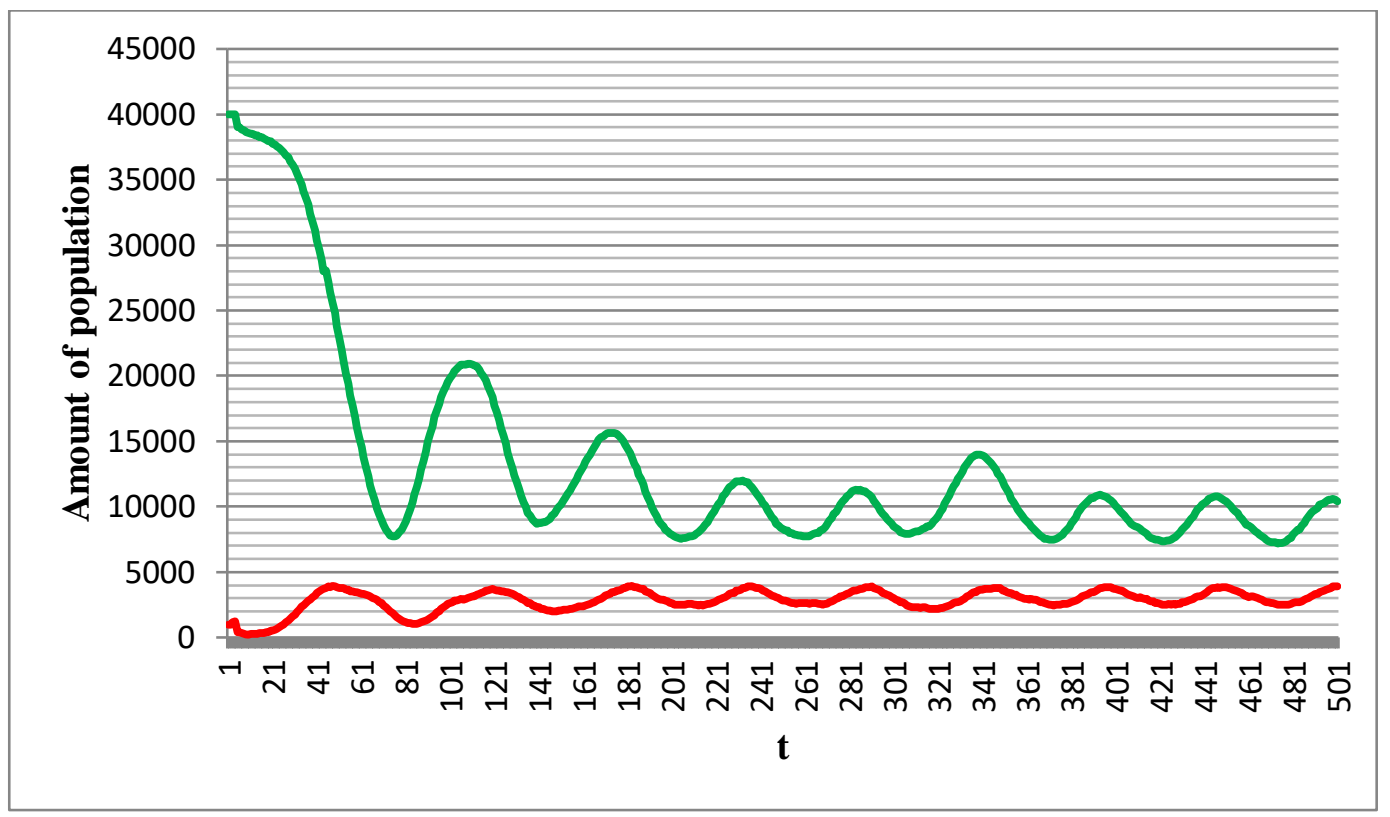

Fig. 12. Changes of population at $\tau=30$.

According to the Fig. 9-12, it can be concluded that taking into account the delay effect can improve the accuracy of predictive modeling the interacting biological population evolution. As we can see that, the change of population is approaching the field data at increasing the $\tau$ parameter. Numerical experiments have shown that the results of population dynamics modeling coincide with the solution of equation (2) at the qualitative level (Fig. 2). The solution of the model problem at high values $\tau$ has the complex oscillations. The solution of the model problem gives a fast output to the stationary regime with a single significant deviation with the less delay.

The numerical implementation of the modified Conway algorithm made it possible to determine nontrivial input data that affect on the dynamics of environmental processes, tend to some established stationary or oscillatory regime. Although it is known that the initial conditions are not so significant characteristics in population dynamics.

Conclusion. A variant of the cellular automation, modeling the regulation processes of interacting biological population dynamics taking into account the delay effect, was considered. The application was developed for a computer in C\# for modeling the nonlinear interaction of the cellular automation. Experiments were performed on the basis of developed application for researching various effects, including the delay, occurring at different input parameters of the cellular automation (the rules of transition). The algorithm of cell transformation includes three dynamically interacting factors: the ontogenetic delay, the need to restore resources for the further development of the population, and the diffusion component. The developed numerical implementation of the cellular automaton was based on the hypothesis that the delayed regulation does not belong to the properties of species or only the environment, but it is an additive characteristic of nonlinear interaction process of the researched biological populations. 


\section{References}

1. Cooke B., NealiS V., Regniere J.: Insect Defoliators as Periodic Disturbances in Northern Forest Ecosystems. Plant disturbance ecology: the process and the response. Burlington, Elsevier, 487-525 (2007).

2. Toffoli T., Margolus N.: Cellular automata machines. Mir, Moscow, 280 p. (1991).

3. Stephen Wolfram: A New Kind of Science. Wolfram Media, 1197 p. (2002).

4. Gardner M. Mathematical Games - The fantastic combinations of John Conway's new solitaire game «life». Scientific American. 223, 120-123 (1970).

5. Astafjev G.B., Koronovskii A. A., Khramov A.E.: Cellular automata. Saratov: publishing House of Gosunts «College», 24 p. (2003).

6. Sukhinov A.I., Nikitina A.V., Sidoryakina V.V., Semenyakina A.A.: Justification and modeling of the turbulent exchange coefficients of reservoirs on the basis of stochastic method. THEORY PROBAB. APPL. Society for Industrial and Applied Mathematics. 62 (4), 640-674 (2018). DOI. 10.1137/S0040585X97T988861.

7. Riznichenko G.Yu.: Lectures on mathematical models in biology. Moscow-Izhevsk: RCD, 232 p. (2002).

8. Hutchinson G. An Introduction to Population Ecology. New Haven: Yale University Press, 260 p. (1978).

9. Andronov A.A., Leontovich E.A., Gordon I.I., Maier A.G.: Theory of bifurcations of dynamical systems on the plane. Nauka, Moscow, 485 p. (1967).

10. Berezansky L., Braverman E.: On oscillation of a food-limited population model with time delay. Abstr. Appl. Anal. 2003 (1), 55-66 (2003).

11. Nicholson A.: An outline of the dynamics of animal populations. Australian Journal of Zoology. 2 (1), 9-65 (1954).

12. Gurney W., Blythe S., Nisbet R.: Nicholson's blowflies revisited. Nature, 287, 17-21 (1980).

13. Nikitina A.V., Sukhinov A.I., Ugolnitsky G.A., Usov A.B., Chistyakov A.E., Puchkin M.V., Semenov I.S.: Optimal control of sustainable development in the biological rehabilitation of the Azov Sea. Mathematical Models and Computer Simulations. 9 (1), 101-107 (2017).

14. Kamakin A.M., Khodorevskaya R.P., Paritzky Y.A.: Impact of a new invader ctenophore Mnemiopsis leidyi (A. Agassis, 1865) on the main elements of the Caspian Sea ecosystem. Vestnik of ASTU. Series: fisheries. 1 (2018).

15. «Analytical GIS» Homepage, http://geo.iitp.ru/index.php, last accessed 2018/10/15.

16. Sukhinov A.I, Chistyakov A.E Semenyakina A.A., Nikitina A.V.: Numerical modeling of the ecological state of the Azov Sea with application of schemes of increased accuracy on a multiprocessor computer system. Computer Researches and Modeling. 1(8), 151-168 (2016).

17. Marchuk G.I.: Mathematical modeling in the environmental problem. Nauka, Moscow (1982).

18. Perevaryukha A.Y.: Delay in the regulation of population dynamics - cellular automation model. Dinamicheskie Sistemy. 7(35), 157-165 (2017). 


\section{Authors:}

Nikitina Alla Valeryevna, Southern Federal University (Chekhov str., 2, Taganrog, Russian Federation), Doctor of Technical Science, Associate professor.

Filina Alena Aleksandrovna, Supercomputers and Neurocomputers Research Center, Co Ltd.

(Italyansky lane, 106, Taganrog, Russian Federation), Candidate of Technical Science, Researcher 


\title{
Математическое моделирование процесса запаздывания в регуляции популяционной
} динамики на основе теории клеточных автоматов*

\author{
А.В. Никитина, В.М. Козлов ${ }^{* *}$, А.А. Филина ${ }^{* * *}$ \\ Южный федеральный университет, Таганрог, Российская Федерация \\ ООО «НИЦ супер-ЭВМ и нейрокомпьютеров», Таганрог, Российская Федерация
}

Работа посвящена изучению и параметризации эффекта запаздывания при регуляции процессов биологической кинетики для взаимодействующих популяций, в том числе модификация математической модели для описания развития популяционных флуктуаций. Для анализа модельных сценариев динамики нелинейно взаимодействующих биологических популяций с учетом факторов, оказывающих существенное влияние на характер протекания изучаемых процессов, разработана численная реализация модифицированного алгоритма Конвея для клеточного автомата с троичным состоянием клеток. Условия трансформации состояния клеток показывают, что формализуемое запаздывание может относиться к динамике взаимодействия видов и поддерживающей условия жизни среды. Предложена численная реализация принципиально отличного варианта клеточного автомата, моделирующего процессы регуляции популяционной динамики с учетом эффекта запаздывания на основе трех динамически взаимодействующих факторов: онтогенетической задержки, необходимости восстановления ресурсов и диффузионной составляющей, зависящей от темпа развития особей популяции.

Ключевые слова: клеточный автомат, популяционная динамика, эффект запаздывания, математическая модель, алгоритм, программа.

\section{Авторы:}

Никитина Алла Валерьевна, Южный Федеральный Университет (347928, Россия, Ростовская область, г. Таганрог, пер. Некрасовский, 44), доктор технических наук, профессор.

Филина Алёна Александровна, Научно-исследовательский центр супер-ЭВМ и нейрокомпьютеров (347900, Россия, Ростовская область, г. Таганрог, пер. Итальянский, дом 106), кандидат технических наук, научный сотрудник.

\footnotetext{
* Работа выполнена при поддержке РНФ, проект № 17-11-01286.

${ }^{* *}$ E-mail: nikitina.vm@gmail.com.

*** E-mail: j.a.s.s.y@mail.ru.
} 